\title{
A double-blind, placebo-controlled, cross-over study to establish the bifidogenic effect of a very-long-chain inulin extracted from globe artichoke (Cynara scolymus) in healthy human subjects
}

\author{
Adele Costabile ${ }^{1}$, Sofia Kolida ${ }^{1}$, Annett Klinder ${ }^{1}$, Eva Gietl $^{2}$, Michael Bäuerlein ${ }^{3}$, Claus Frohberg $^{2}$, \\ Volker Landschütze ${ }^{2}$ and Glenn R. Gibson ${ }^{1}$ \\ ${ }^{1}$ Food Microbial Sciences, School of Food and Nutritional Sciences, University of Reading, Reading RG6 6AP, UK \\ ${ }^{2}$ Bayer BioScience GmbH, Hermannwwerder 20a, 14473 Potsdam, Germany \\ ${ }^{3}$ Bayer Cropscience AG, Alfred-Nobel-Strasse 50, 40789 Monheim, Germany
}

(Received 16 December 2009 - Revised 17 March 2010 - Accepted 26 March 2010 - First published online 1 July 2010)

\begin{abstract}
There is growing interest in the use of inulins as substrates for the selective growth of beneficial gut bacteria such as bifidobacteria and lactobacilli because recent studies have established that their prebiotic effect is linked to several health benefits. In the present study, the impact of a verylong-chain inulin (VLCI), derived from globe artichoke (Cynara scolymus), on the human intestinal microbiota compared with maltodextrin was determined. A double-blind, cross-over study was carried out in thirty-two healthy adults who were randomised into two groups and consumed $10 \mathrm{~g} / \mathrm{d}$ of either VLCI or maltodextrin, for two 3-week study periods, separated by a 3-week washout period. Numbers of faecal bifidobacteria and lactobacilli were significantly higher upon VLCI ingestion compared with the placebo. Additionally, levels of Atopobium group significantly increased, while Bacteroides-Prevotella numbers were significantly reduced. No significant changes in faecal SCFA concentrations were observed. There were no adverse gastrointestinal symptoms apart from a significant increase in mild and moderate bloating upon VLCI ingestion. These observations were also confirmed by in vitro gas production measurements. In conclusion, daily consumption of VLCI extracted from globe artichoke exerted a pronounced prebiotic effect on the human faecal microbiota composition and was well tolerated by all volunteers.
\end{abstract}

Prebiotics: Bifidogenic effect: Gas production: Intestinal microflora

In the last decade functional foods in human and animal nutrition have gained in importance. Within this field of research, scientific concepts underpinning directed modulation of the human gut microbiota towards a more beneficial composition have been developed ${ }^{(1,2)}$. The prebiotic approach advocates targeting selected indigenous beneficial bacteria through non-viable food ingredients ${ }^{(3)}$. The concept was recently updated by Gibson et al. ${ }^{(4)}$, and the weight of evidence for established and emerging prebiotics reviewed ${ }^{(5)}$. Much of the interest in the development of prebiotics aims at non-digestible oligosaccharides. These are short-chain carbohydrates that consist of two to twenty saccharide units. Examples include inulin-type fructans, galacto-oligosaccharides, isomaltooligosaccharides, xylo-oligosaccharides, soya-oligosaccharides, gluco-oligosaccharides and lacto-sucrose ${ }^{(6,7)}$, although each of these varies in their prebiotic potential.

Inulin and fructo-oligosaccharides are plant $\beta$ (2-1) fructans with a degree of polymerisation (DP) ranging from 2 to 60 or more for inulin, or from 2 to 10 for oligofructose ${ }^{(8)}$.

There is a high degree of variability in DP distribution among products derived from different plant origins. Inulin derived from globe artichoke (Cynara scolymus) generally has the highest $\mathrm{DP}^{(9)}$ whereas onion, garlic, Jerusalem artichoke (Heliantus tuberosus), leeks, asparagus and banana have lower $\mathrm{DP}^{(8)}$. The inulin content of Jerusalem artichoke ranges from 17 to $20.5 \%$ on a fresh weight basis. Praznik et $a .^{(10)}$ found that $74 \%$ of Jerusalem artichoke inulin had a DP $<19$ while $20 \%$ was between DP 19 and 40 and $6 \%$ had a DP $>40$. The inulin content of chicory (Chichorium intybus), harvested from roots, ranged from 15.2 to $20.5 \%$, of which $55 \%$ had a DP of 2 to $19,28 \%$ with DP between 19 and 40 , and $17 \%$ with DP $>40^{(8)}$. The globe artichoke root contains inulin in a range from 30.6 to $36.7 \%$ on a DM basis $^{(11)}$ with a maximum DP of about $200^{(12)}$

DP distribution and molecular weight are influenced by the harvesting conditions and additionally the extraction process could influence the molecular weight distribution or composition of the inulin and fructo-oligosaccharides ${ }^{(13)}$. DP distribution and molecular weight in turn influence the physico-chemical properties of inulins such as solubility, thickening power and resistance to crystal formation.

Research, to date, on prebiotic potential has been limited to inulin-type fructans derived from chicory roots, whereas inulin or fructo-oligosaccharides derived from other plant sources,

Abbreviations: DP, degree of polymerisation; FISH, fluorescence in situ hybridisation; VLCI, very-long-chain inulin.

* Corresponding author: Dr A. Costabile, fax +44 118931 0080, email a.costabile@reading.ac.uk 
such as globe artichoke, have received little attention. Only recently the interest in their tubers for food purposes has increased mainly due to their content of several potentially bioactive ingredients such as inulin and fructo-oligosaccharides, naturally occurring fructose, minerals, essential amino acids, vitamins and flavonoids ${ }^{(14)}$.

Very-long-chain inulin (VLCI) which is extracted from globe artichoke has an average DP of between 50 and 103 and is used for inhibiting the growth of ice crystals in frozen foodstuffs, preferably frozen confections. Its DP is considerably higher than that of the long-chain inulin Beneo ${ }^{\circledR} \mathrm{HP}$ investigated so far. Beneo ${ }^{\circledR} \mathrm{HP}$ is extracted from chicory roots by applying physical separation techniques to eliminate all oligomers resulting in an average DP higher than 23 but mainly lower than 60 .

Inulin has thus far been reported to have a positive effect on the gut microbiota at doses ranging from 4 to $40 \mathrm{~g} / \mathrm{d}^{(15-21)}$. Most physiological changes that inulin induces in the host are probably effected by bacterial metabolites. The most important metabolites are the SCFA acetate, propionate and butyrate $^{(22)}$. SCFA acidify the colonic environment, which is beneficial for certain bacteria such as bifidobacteria and lactobacilli, and detrimental to the growth of potential pathogenic species ${ }^{(23,24)}$. SCFA are rapidly absorbed from the colon and are then metabolised in various tissues: butyrate by the colonic epithelium, propionate and acetate partly by the liver and acetate partly by muscle and other peripheral tissues ${ }^{(3,24)}$.

In the present study, the potential of VLCI to beneficially modulate the gastrointestinal microbiota and their activities was determined against maltodextrin (placebo). The objective was to assess the capacity of VLCI compared with the placebo to selectively increase numbers of bifidobacteria and lactobacilli in faeces.

Here, we present the findings of a double-blind, placebocontrolled cross-over study with thirty-two free-living healthy subjects randomised into two groups and fed either VLCI $(10 \mathrm{~g} / \mathrm{d})$ or maltodextrin $(10 \mathrm{~g} / \mathrm{d})$ for 3 weeks. Changes within the gut microbiota and fermentation profiles were determined in stool samples before and after treatment and gastrointestinal symptoms and stool characteristics were recorded. In order to corroborate the in vivo results on gas production without the bias of volunteer perception, the in vitro gas production kinetics in five randomly selected volunteers at baseline and after the 3 weeks of inulin or maltodextrin intake was also examined.

\section{Materials and methods}

Molecular-weight analysis of very-long-chain inulin by gel permeation chromatography with light scattering and refractive index detection (GPC-RI-MALLS system)

VLCI (no. WO/2009/000535 - Use of very long chain inulin for inhibiting the growth of ice crystals in a frozen foodstuff, patent of Bayer Cropscience AG, Monheim, Germany) and Beneo ${ }^{\circledR} \mathrm{HP}$ (Orafti, Tienen, Belgium) were dissolved in extra-pure water at a concentration of $0.5 \%(\mathrm{w} / \mathrm{v})$. The solutions were heated at $95^{\circ} \mathrm{C}$ for $30 \mathrm{~min}$. Then, the polymers were analysed using the following devices: Alliance chromatography system (Waters Corp., Milford, MA, USA), DAWN-EOS light scattering detector (Wyatt Technology,
Santa Barbara, CA, USA) with $\lambda_{0}=658 \mathrm{~nm}$ and sixteen detectors in the range of angles from 14.4 to $163 \cdot 3^{\circ} \mathrm{C}, \mathrm{K} 5$ flow cell. The polymers were fractionated on a pre-column and three columns having the separation ranges of $300-10^{4}$, $5 \times 10^{4}-2 \times 10^{6}$ and $10^{6}-10^{8}$ (SUPREMA-Gel; PSS Polymer Standards Service GmbH, Mainz, Germany). For fractionation of the samples $100 \mu \mathrm{l}$ of this solution were injected at a temperature of $30^{\circ} \mathrm{C}$ and a flow rate of $0.8 \mathrm{ml} / \mathrm{min}$ with $0 \cdot 05 \mathrm{~mm}-\mathrm{NaNO}_{3}$ as the eluent. The Astra V 5.1.8.0 program (Wyatt Technology) was used to analyse the molecularweight distribution of the samples.

\section{Polymer chain distribution analysis of inulin by high- performance anion exchange chromatography coupled with pulsed amperometric detection (known as HPAEC-PAD)}

VLCI and Beneo ${ }^{\circledR} \mathrm{HP}$ (Orafti) inulins $(5 \%$, w/v) were solubilised completely in boiling water and filtered through a $0 \cdot 22 \mu \mathrm{m}$ filter. Filtrates with a concentration of $0.02 \%$ inulin were used for analysis. To map VLCI profiles and to determine the DP, a Dionex series 500 ion chromatograph (DX 500; Dionex, Idstein, Germany) coupled with a pulsed amperometric detector (Carbo-Pac PA-100 column) was used. During the analysis, the carbohydrates were eluted with $150 \mathrm{~mm}-\mathrm{NaOH}$ and $1 \mathrm{M}$-sodium acetate in $150 \mathrm{~mm}-$ $\mathrm{NaOH}$ solution being used as eluents $\mathrm{A}$ and $\mathrm{B}$, according to the following time and composition program (eluents $\mathrm{A}$ and $\mathrm{B}$ were expressed as a percentage $(\mathrm{v} / \mathrm{v}))$ : 0 to $5 \mathrm{~min}, 100 ; 5$ to $40 \mathrm{~min}, 72$ and $28 ; 40$ to $70 \mathrm{~min}, 50$ and $45 ; 70$ to $75 \mathrm{~min}, 0$ and $100 ; 75$ to $80 \mathrm{~min}, 100 ; 80$ to $85 \mathrm{~min}, 100$ and $0 ; 85$ to $90 \mathrm{~min}, 100$. The flow rate was set at $1 \mathrm{ml} / \mathrm{min}$. All mobile phases were kept under pressure by sparging with $\mathrm{He}$ in order to prevent the subsequent production of carbonate, which would act as a displacing ion and reduce retention times. Chromatographic data were collected and plotted using the Dionex 500 chromatography workstation.

\section{Subjects}

Thirty-two healthy volunteers (aged 20-42 years, mean age 25 years; eighteen females, fourteen males) were recruited from the Reading area. Written consent was obtained from all participants and the study protocol was approved by the Ethics and Research Committee of the University of Reading.

Inclusion criteria for participation in the study were: aged $18-50$ years; BMI of $20-30 \mathrm{~kg} / \mathrm{m}^{2}$; good general health. Volunteers with evidence of physical or mental disease, major surgery, history of drug abuse, severe allergy or a history of severe abnormal drug reaction and smokers were excluded. Volunteers were also excluded if pregnant, lactating or planning pregnancy. Intake of an experimental drug within 4 weeks before study, former participation in a prebiotic, probiotic or laxative trial within 3 months, or use of antibiotics within 6 months before the study, chronic constipation, diarrhoea or other chronic gastrointestinal complaint (for example, irritable bowel syndrome) were all exclusion criteria. Any intake of drugs active on gastrointestinal motility, antibiotic treatment or any class of laxative was not permitted. Any medication taken throughout the duration of the study was recorded in diaries. Volunteers were instructed not to alter their usual diet or fluid intake during the trial periods; 
however, they were asked to refrain from consuming prebiotics and probiotics including live yoghurts and fermented milk drinks.

\section{Dietary intervention study}

The dietary intervention study was performed in a doubleblind, randomised, placebo-controlled cross-over manner. Thirty-two healthy volunteers were recruited onto the study, but one volunteer dropped out due to personal reasons. For a period of $14 \mathrm{~d}$ before the dietary intervention study, volunteers followed a restricted diet as described earlier. Thirtyone subjects were randomly allocated into one of two groups.

The first group ( $n$ 18) consumed VLCI ( $10 \mathrm{~g} / \mathrm{d}$; Bayer BioScience $\mathrm{GmbH}$, Hermannswerder, Potsdam, Germany) for 3 weeks, and then after a 3-week washout period, they consumed the placebo (maltodextrin; Roquette, Lestrem, France) $(10 \mathrm{~g} / \mathrm{d})$ for 3 weeks. The second group ( $n$ 13) received first the placebo $(10 \mathrm{~g} / \mathrm{d})$ for 3 weeks, and then after a 3 -week washout, they consumed VLCI $(10 \mathrm{~g} / \mathrm{d})$ for another 3-week treatment period. Each product was given for 3 weeks, followed by 3 -week washout periods during which no prebiotic was consumed. The composition of globe artichoke root (cv. Madrigal; Nunhems, Haelen, The Netherlands) derived VLCI was as follows: inulin, $97.5 \%$, moisture, $3 \cdot 1 \%$, sugars (glucose, fructose, sucrose), $0.2 \%$; ash, $0.4 \%$.

All test products were packaged, labelled and randomised by Bayer BioScience GmbH (Hermannswerder, Potsdam, Germany) before the study, and the study was blinded to both the investigators in the University of Reading and the volunteers. Volunteers were asked to keep diaries throughout the study to record stool frequency, consistency (constipation, hard, formed, soft or diarrhoea), abdominal pain (none, mild, moderate or severe), intestinal bloating (none, mild, moderate or severe) and flatulence (none, mild, moderate or severe) on a daily basis. Any concomitant medication and adverse events were also recorded.

Faecal samples were collected from each volunteer at five different points, before and after each treatment: at baseline, before inulin intake (pre-VLCI), during VLCI intake, at washout 1 (post-VLCI), before maltodextrin (pre-maltodextrin), during maltodextrin intake, at washout 2 (post-maltodextrin).

\section{Collection and stool sample preparation}

Freshly voided faecal samples were stored in an anaerobic cabinet $\left(10 \% \mathrm{H}_{2} ; 10 \% \mathrm{CO}_{2} ; 80 \% \mathrm{~N}_{2}\right)$ for no longer than $2 \mathrm{~h}$ before processing. Samples were diluted 1:10 (w/w) with PBS (0.1 M; pH 7.0) and mixed in a Stomacher 400 (Seward, Thetford, Norfolk, UK) for $2 \mathrm{~min}$ at normal speed.

\section{Enumeration of faecal microbial populations by fluorescence} in situ hybridisation

Fluorescence in situ hybridisation (FISH) was performed as described by Martín-Peláez et al. ${ }^{(25)}$. The composition of hybridisation and wash buffers depends on the rRNA-targeted oligonucleotide probe as reported in probeBase (http://www. microbial-ecology.net/probebase) and was used accordingly. Briefly, samples $(375 \mu \mathrm{l})$ of $1 ; 10(\mathrm{w} / \mathrm{w})$ stool sample suspension in PBS were fixed overnight at $4^{\circ} \mathrm{C}$ with $4 \%(\mathrm{w} / \mathrm{v})$ filtered paraformaldehyde ( $\mathrm{pH} 7 \cdot 2)$ in a ratio of 1:4 (v/v), washed twice with filtered PBS $(0.2 \mu \mathrm{m}$ pore size), resuspended in $300 \mathrm{ml}$ of a PBS-ethanol mixture $(1: 1, \mathrm{v} / \mathrm{v})$ and then stored at $-20^{\circ} \mathrm{C}$ for up to 3 months. For the hybridisations, $20 \mu \mathrm{l}$ of each sample were pipetted onto Teflon- and poly-L-lysine-coated, six-well (10 mm diameter each) slides (Tekdon Inc., Myakka City, FL, USA). To permeabilise the cells for use with probe Lab158, samples were treated with $50 \mu \mathrm{l}$ of lysozyme $(1 \mathrm{mg} / \mathrm{ml}$ in $100 \mathrm{~mm}$-2-amino-2-hydroxymethyl-propane-1,3-diol- $\mathrm{HCl}, \mathrm{pH} 8.0$ ) at $37^{\circ} \mathrm{C}$ for $15 \mathrm{~min}$ before being washed $(2-3 \mathrm{~s})$ in water and were finally dehydrated in the ethanol series $(50 \%, 80 \%$ and $96 \%$ (v/v) ethanol, $3 \mathrm{~min}$ each). The probe $(5 \mathrm{ng} / \mu \mathrm{l}$ probe in hybridisation buffer) was applied onto the surface of each well. Hybridisations were performed for $4 \mathrm{~h}$ in an ISO20 oven (Grant Boekel, Cambridge, Cambs, UK). For the washing step, slides were placed in $50 \mathrm{ml}$ of wash buffer containing $20 \mu \mathrm{l}$ of 4, 6-diamidino-2-phenylindole dihydrochloride (DAPI; $50 \mathrm{ng} / \mu \mathrm{l}$; Sigma, St Louis, MO, USA) for $15 \mathrm{~min}$. They were then washed $(2-3 \mathrm{~s})$ in ice-cold water and dried under a stream of compressed air. Then $5 \mu$ l of antifade reagent (polyvinyl alcohol mounting medium with $\mathrm{DABCO}^{\mathrm{TM}}$ antifading; Sigma) were added to each well and a coverslip was applied. Slides were stored in the dark at $4^{\circ} \mathrm{C}$ (for a maximum of $3 \mathrm{~d}$ ) until cells were counted under a Nikon E400 Eclipse microscope (Nikon, Kingston upon Thames Surrey, UK). DAPI slides were visualised with the aid of a DM 400 filter and probe slides with the aid of a DM 575 filter. All probes were Cy3-labelled and synthesised by Sigma Aldrich. Table 1 gives the details of probes used in the present study ${ }^{(26-33)}$.

\section{Faecal SCFA analysis}

Samples $(1 \mathrm{ml})$ of 1:10 (w/w) stool sample suspension in PBS were dispensed into $1.5 \mathrm{ml}$ tubes and centrifuged at $13000 \mathrm{~g}$ for $5 \mathrm{~min}$ to pellet bacteria and other solids. Supernatant fractions were filtered using $0.2 \mu \mathrm{m}$ polycarbonate syringe filters (Whatman International Ltd, Maidstone, Kent, UK) and injected $(200 \mu \mathrm{l})$ into an HPLC system (Merck, Whitehouse Station, NJ, USA) equipped with refractive index (RI) detection. The column used was an ion-exclusion REZEX ROA organic acid column (Phenomenex, Inc., Macclesfield, Cheshire, UK) maintained at $85^{\circ} \mathrm{C}$. Sulfuric acid in HPLC-grade water $(0.0025 \mathrm{~mm})$ was used as the eluent and the flow rate was maintained at $0.5 \mathrm{ml} / \mathrm{min}^{(25)}$. The carbonic acids in the samples were quantified through calibration curves of lactic, acetic, propionic and butyric in concentrations ranging between 2.5 and $100 \mathrm{~mm}$. Peaks were integrated using Atlas Lab managing software (Thermo Lab Systems, Mainz, Germany).

\section{In vitro rate of gas production}

A pressure technique ${ }^{(34)}$ was used to monitor the cumulative and rate of gas production in five randomly selected volunteers participating in the feeding study at baseline, and upon completion of treatments (VLCI and maltodextrin).

Pre-reduced gut model culture medium $(80 \mathrm{ml})^{(35)}$ was dispensed into clean serum vials ( $125 \mathrm{ml}$ working volume; Belco Glass Inc., Vineland, NJ, USA) in an anaerobic cabinet (10\% $\mathrm{H}_{2}, 10 \% \mathrm{CO}_{2}, 80 \% \mathrm{~N}_{2}$ ) and sealed with a gas-impermeable butyl rubber septum and aluminium cap. Vials were 
Table 1. Probes used for fluorescence in situ hybridisation analysis of bacterial populations in human faeces

\begin{tabular}{|c|c|c|c|c|c|}
\hline Short name & Accession no. & Full name† & Sequence $\left(5^{\prime}\right.$ to $\left.3^{\prime}\right)$ & Target species & Reference \\
\hline Bif164 & pB-00037 & S-G-Bif-0164-a-A-18 & CATCCGGCATTACCACCC & Most Bifidobacterium spp. and Parascardovia denticolens & Langendijk et al. (1995) $)^{(26}$ \\
\hline Lab158 & ND & S-G-Lab-0158-a-A-20 & GGTATTAGCAYCTGTTTCCA & $\begin{array}{l}\text { Most Lactobacillus, Leuconostoc and Weissella spp.; Lactococcus } \\
\text { lactis; all Vagococcus, Enterococcus, Melisococcus, } \\
\text { Tetragenococcus, Catellicoccus, Pediococcus and } \\
\text { Paralactobacillus spp. }\end{array}$ & Harmsen et al. (1999) ${ }^{(27)}$ \\
\hline Вас303 & pB-00031 & S-*-Bacto-0303-a-A-17 & CCAATGTGGGGGACCTT & $\begin{array}{l}\text { Most Bacteroides sensu stricto and Prevotella spp.; all } \\
\text { Parabacteroides; Barnesiella viscericola and Odoribacter } \\
\text { splanchnicus }\end{array}$ & Manz et al. $(1996)^{(28)}$ \\
\hline Chis 150 & pB-00962 & S-*-Chis-0150-a-A-23 & TTATGCGGTATTAATCTYCCTTT & $\begin{array}{l}\text { Most members of Clostridium cluster I; all members of } \\
\text { Clostridium cluster II; Clostridium tyrobutyricum; Adhaeribacter } \\
\text { aquaticus and Flexibacter canadensis (family Flexibacteriaceae); } \\
\text { (Eubacterium) combesii (family Propionibacteriaceae) }\end{array}$ & Franks et al. $(1998)^{(29)}$ \\
\hline Rbro730 & pB-00558 & S-*-Rbro-730-a-A-18 & TAAAGCCCAGYAGGCCGC & $\begin{array}{l}\text { Ruminococcus bromii-like; Clostridium sporosphaeroides and } \\
\text { Clostridium leptum }\end{array}$ & Harmsen et al. $(2002)^{(30)}$ \\
\hline Rfla729 & pB-00557 & S-*-Rfla-729-a-A-18 & AAAGCCCAGTAAGCCGCC & Ruminococcus albus and Ruminococcus flavefaciens & Harmsen et al. (2002) ${ }^{(30)}$ \\
\hline Ato291 & pB-00943 & S-*-Ato-0291-a-A-17 & GGTCGGTCTCTCAACCC & $\begin{array}{l}\text { Atopobium, Colinsella, Olsenella and Eggerthella spp.; } \\
\text { Cryptobacterium curtum; Mycoplasma equigenitalium and } \\
\text { Mycoplasma elephantis }\end{array}$ & Harmsen et al. $(2000)^{(31)}$ \\
\hline Erec482 & pB-00963 & S-*-Erec-0482-a-A-19 & GCTTCTTAGTCARGTACCG & $\begin{array}{l}\text { Most members of Clostridium cluster XIVa; Syntrophococcus } \\
\text { sucromutans, (Bacteroides) galacturonicus and (Bacteroides) } \\
\text { xylanolyticus, Lachnospira pectinschiza and Clostridium } \\
\text { saccharolyticum }\end{array}$ & Franks et al. $(1998)^{(29)}$ \\
\hline Ehal1469 & pB-00554 & ND & CCA GTT ACC GGC TCC ACC & $\begin{array}{l}\text { Eubacterium hallii, Clostridium herbivorans, Clostridium } \\
\text { polysaccharolyticum }\end{array}$ & Harmsen et al. $(2002)^{(30)}$ \\
\hline Ecyl387 & pB-00556 & ND & CGC GGC ATT GCT CGT TCA & $\begin{array}{l}\text { Eubacterium cylindroides, Clostridium innocuum, Eubacterium } \\
\text { biforme, Eubacterium tortuosum, Eubacterium dolichum, } \\
\text { Streptococcus pleomorphus }\end{array}$ & Harmsen et al. $(2002)^{(30)}$ \\
\hline Eub I-II-III & pB-00159-160-161 & S-D-Bact-0338-a-A-18 & GCT GCC TCC CGT AGG AGT & Total bacteria & Amann et al. $(1990)^{(32)}$ \\
\hline Clit135 & pB-00961 & *-Clit-0135-a-A-19 & GTTATCCGTGTGTACAGG & Some of the Clostridium lituseburense group (Clostridium cluster XI) & Franks et al. (1998) (29) \\
\hline Rrec584 & ND & ND & TCAGACTTGCCG(C/T)ACCGC & Roseburia-Eubacterium rectale (a component of cluster XIVa) & Walker et al. (2005) ${ }^{(33)}$ \\
\hline EC1531 & ND & L-S-Eco-1531-a-A-21 & CACCGTAGTGCCTCGTCATC & Escherichia coli & Walker et al. (2005) ${ }^{(33)}$ \\
\hline Prop853 & ND & ND & ATTGCGTTAACTCCGGCAC & Clostridium cluster IX & Walker et al. (2005) ${ }^{(33)}$ \\
\hline
\end{tabular}

ND, no information relating to these probes has been deposited in probeBase (http://www.microbial-ecology.net/probebase).

†Probe designation according to probeBase.

$\ddagger$ These probes were used together in equimolar concentrations (both at $50 \mathrm{ng} / \mathrm{\mu l}$ ). Formamide $(20 \%)$ was included in the hybridisation buffer. 
autoclaved and placed overnight in a $37^{\circ} \mathrm{C}$ incubator. The culture medium consisted of the following $(\mathrm{g} / \mathrm{l})$ dissolved in distilled water: starch (potato), 5.0; pectin (citrus), 2.0; guar gum, 1.0; mucin (porcine gastric type III), 4.0; xylan (oatspelt), 2.0; arabinogalactan (larch wood), 2.0; inulin (Beneo ${ }^{\circledR} \mathrm{ST}$; Orafti), 1.0; casein (BDH Ltd, Poole, Dorset, UK), 3.0; peptone water (Oxoid, Basingstoke, Hants, UK), 5·0; tryptone (Oxoid), 5·0; bile salts no. 3 (Oxoid), 0.4; yeast extract (Oxoid), 4.5; $\mathrm{FeSO}_{4} \cdot 7 \mathrm{H}_{2} \mathrm{O}, 0 \cdot 005 ; \mathrm{NaCl}$ (Fisher Scientific, Springfield, NJ, USA), 4.5; $\mathrm{KCl}$ (VWR International, Lutterworth, Leics, $\mathrm{UK}), 4 \cdot 5 ; \mathrm{KH}_{2} \mathrm{PO}_{4}, 0 \cdot 5 ; \mathrm{MgSO}_{4} \cdot 7 \mathrm{H}_{2} \mathrm{O}, 1 \cdot 25 ; \mathrm{CaCl}_{2} \cdot 6 \mathrm{H}_{2} \mathrm{O}$, $0 \cdot 15$; $\mathrm{NaHCO}_{3}, 1 \cdot 5$; cysteine $\mathrm{HCl}, 0 \cdot 8$; hemin, 0.05; Tween 80, $1.0 \mathrm{ml}$; vitamin $\mathrm{K}_{1}, 10 \mu \mathrm{l}$. Unless otherwise stated, all chemicals were obtained from Sigma-Aldrich (Poole, Dorset, UK).

Each vial containing a volume of $90 \mathrm{ml}$ was inoculated with $10 \mathrm{ml}$ of 1:10 diluted faecal slurry, prepared as above, via a sterile syringe, giving a final volume of $100 \mathrm{ml}$.

The gas production potential of the faecal flora after treatment was evaluated by recording the head space pressure (pounds per square inch; psi) of each vial. Seven replicate vials were prepared for each donor. Vials were incubated at $37^{\circ} \mathrm{C}$ and were continuously shaken. Pressure readings were obtained every $3 \mathrm{~h}$ for a $27 \mathrm{~h}$ fermentation period by piercing the rubber caps with a U200/66 needle adaptor connected to a pressure transducer (type 2200BGF150WD3DA; Keller Ltd, Dorchester, Dorset, UK) with a T443A digital panel meter (Bailey and Makey Ltd, Birmingham, UK). Pressure readings (psi) were converted into gas volume ( $\mathrm{ml}$ ) using an established linear regression of pressure recorded in the same vials with known air volumes at the incubation temperature. Gas production data were fitted to the model proposed by France et $a l .^{(36)}$ using the program CurveExpert (version 1.37; Daniel G Hyams, Hixson, TN, USA) to provide parameters describing cumulative gas release in terms of potential gas production $(\mathrm{A} ; \mathrm{ml})$, lag time $(\mathrm{T} ; \mathrm{h})$, time to half-asymptote $(\mathrm{T} / 2 ; \mathrm{h})$ and fractional rate of gas production at $\mathrm{T} / 2(\mu ;$ per $\mathrm{h})$.

\section{Statistical analysis}

A general linear model was used to test for time-dependent effects $\left(\right.$ Genstat $^{\circledR}$ for Windows ${ }^{\circledR}$ 8th edition; VSN International, Hemel Hempstead, Herts, UK). When there was no significant effect for 'sequence' all time points were included and subsequent statistical analyses were performed using one-way ANOVA, including post hoc tests appropriate for the individual datasets (Tukey's post test with significance set at $P<0 \cdot 05$ ). We used GraphPad Prism (version 5.0; Graph-Pad Software, Inc., San Diego, CA, USA) for FISH, SCFA and gas production analysis.

The occurrence and intensity of gastrointestinal symptoms were scored in the run-in period during the intervention period ( 3 weeks). Volunteers were requested to rank their wellbeing with respect to gastrointestinal complaints, such as abdominal pain, intestinal bloating, flatulence, nausea, borborygmi, diarrhoea and constipation. The respective ranks given were: $0=$ none; $1=$ mild; $2=$ moderate; $3=$ severe. Moreover, stool frequency and consistency were also monitored and ranked as follows: $0=$ watery/diarrhoeal; $1=$ soft; $2=$ normal; $3=$ hard. Statistical analyses were also conducted using GraphPad Prism (version 5; Graph-Pad Software, Inc.).

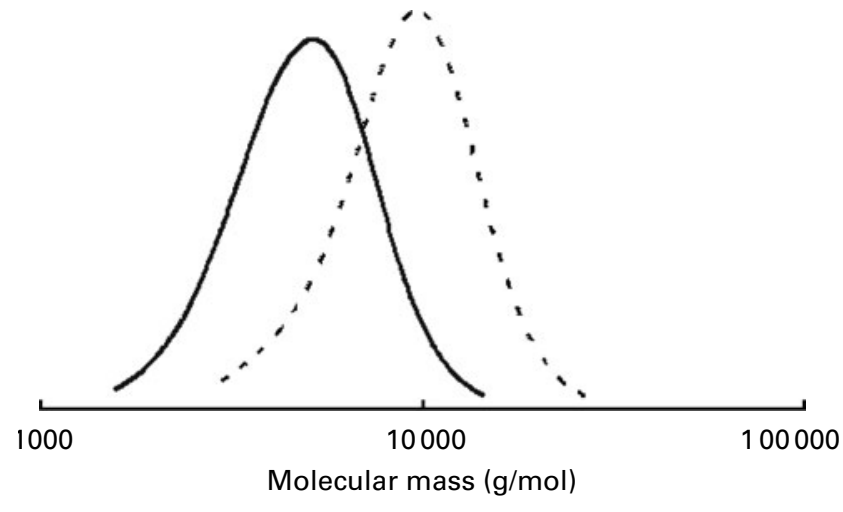

Fig. 1. Gel permeation chromatography with light scattering and refractive index detection (GPC-RI-MALLS system; Mainz, Germany). (一), Beneo ${ }^{\circledR} \mathrm{HP}$ (Orafti, Tienen, Belgium); (--), globe artichoke (Cynara scolymus) inulin (very-long-chain inulin).

The average cumulative gas production in vitro was fitted iteratively to the model ${ }^{(36)}$, using the program CurveExpert (version 1.37; Daniel G Hyams).

\section{Results}

Molecular-weight analysis of very-long-chain inulin by gel permeation chromatography with light scattering and refractive index detection (GPC-RI-MALLS system)

GPC-RI-MALLS chromatograms of VLCI and commercially available chicory root inulin (Beneo ${ }^{\circledR} \mathrm{HP}$ ) are shown in Fig. 1. It is obvious that VLCI has a markedly higher molecular-weight distribution compared with Beneo ${ }^{\circledR} \mathrm{HP}$. The average DP of VLCI was $>55$ as compared with $>23$ in the case of Beneo ${ }^{\circledR} \mathrm{HP}$.

Polymer chain distribution analysis of inulin by highperformance anion exchange chromatography coupled with pulsed amperometric detection (known as HPAEC-PAD)

The inulin profiles of chicory (Beneo ${ }^{\circledR} \mathrm{HP}$ ) and globe artichoke tubers (VLCI) were separated into defined DP ranges. As shown in Fig. 2, chicory inulin (Fig. 2(a)) contains a much higher amount of shorter molecules as compared with globe artichoke inulin (Fig. 2(b)) and the range of high-DP species detected in the VLCI profile clearly exceeds that of chicory.

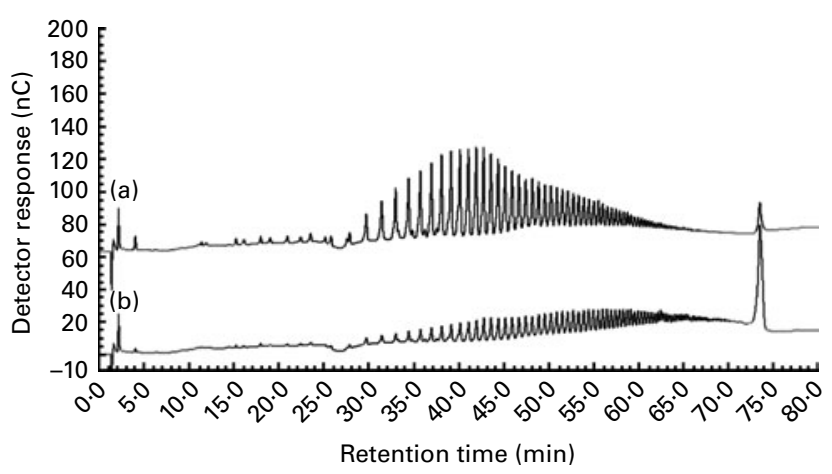

Fig. 2. High-performance anion-exchange chromatography with pulsed amperometric detection (DX 500 Dionex, Idstein, Germany) of (a) Beneo ${ }^{\circledR} \mathrm{HP}$ (Orafti, Tienen, Belgium) and (b) globe artichoke (Cynara scolymus) inulin (very-long-chain inulin). 


\section{Faecal microflora}

The main objective of the study was to assess the impact of consumption of inulin extracted from globe artichoke on the intestinal microbiota. Fourteen 16S rRNA-based FISH probes were used to target predominant groups or species of human faecal bacteria (Table 1) covering $70-80.6 \%$ of total bacteria detected in stool samples. Bacterial numbers at the end of each treatment period - either $10 \mathrm{~g} \mathrm{VLCI} / \mathrm{d}$ or $10 \mathrm{~g}$ maltodextrin/d - were compared with samples obtained before treatment (pre-) and after washout (post-) of the respective treatment. Statistical significance of the results was evaluated using one-way ANOVA with Tukey's post test $(95 \% \mathrm{CI})$. Average faecal bacterial numbers for thirtyone healthy volunteers over the trial period as determined by FISH and expressed as $\log _{10}$ cells/g faeces $(n$ 31) are shown in Table 2.

Total bacterial levels (detected by Eub I-II-III) remained unaffected by intervention. A significant increase in Bifidobacterium numbers was observed during inulin intake compared with samples taken immediately before inulin intervention (2.82-fold increase; $P<0.05)$. There was also a significant difference in bacterial population levels in faeces when comparing inulin and maltodextrin treatment samples. Numbers of bifidobacteria were significantly higher following ingestion of inulin compared with the maltodextrin treatment period (2.75-fold increase; $P<0.001$ ).

Numbers of faecal lactobacilli-enterococci increased significantly with ingestion of VLCI compared with preinulin levels (2.42-fold increase; $P<0.01)$ and the increase was even more pronounced when compared with maltodextrin (5.88-fold increase; $P<0.05)$ in thirty-one volunteers. During the ingestion of maltodextrin, the Lactobacillus-Enterococcus group significantly decreased with respect to pre-maltodextrin (2.64-fold decrease; $P<0.001$ ).
No significant changes were observed between pre-treatment and post-treatment samples for bifidobacteria as well as for lactobacilli counts.

A significant increase in the Atopobium group was observed $(2.83$-fold increase; $P<0.05)$ whereas numbers of the Bacteroides-Prevotella group were reduced (1.77-fold decrease; $P<0.05)$ after consumption of VLCI compared with maltodextrin (Table 2).

No differences were noted in the levels of Escherichia coli and the Eubacterium rectale-Clostridium coccoides group enumerated by the Erec482 probe. The Ehal1469 probe specific for subgroups within the Erec482 (Clostridium cluster XIVa) group did not show significant differences between treatment and placebo. Similarly, the butyrate-producing E. rectale-Roseburia group, also a component of cluster XIVa, was present at no more than $10 \%$ of the total $E$. rectale $-C$. coccoides group at all time points analysed, when enumerated by Rrec584.

Cluster IX representatives (detected by Prop853) and Ruminococcus numbers (Clostridium cluster IV, detected by the Rfla729/Rbro730 probes) did not exhibit any statistically significant changes upon ingestion either of the placebo or VLCI $(P>0.05)$. The Clit135 probe, specific for some members of the $C$. lituseburense group $(C$. lituseburense group - cluster XI) and $C$. histolyticum accounted for no more than $1 \%$ of the total faecal bacteria population.

Specific members of Clostridium cluster XVI (detected by the Ecyl387 probe) did not exhibit changes throughout the duration of the intervention study $(P>0.05)$.

\section{SCFA concentrations}

Table 3 shows the concentrations of faecal SCFA. No significant changes in faecal concentrations of acetic, propionic

Table 2. Average faecal bacterial numbers for thirty-one healthy volunteers over the trial period as determined by fluorescence in situ hybridisation (FISH), expressed as $\log _{10}$ cells $/ g$ faeces

(Mean values and standard deviations)

\begin{tabular}{|c|c|c|c|c|c|c|c|c|c|c|c|c|}
\hline \multirow[b]{2}{*}{ FISH probe name } & \multicolumn{2}{|c|}{ Pre-VLCI } & \multicolumn{2}{|c|}{ VLCl } & \multicolumn{2}{|c|}{ Post-VLCl } & \multicolumn{2}{|c|}{ Pre-maltodextrin } & \multicolumn{2}{|c|}{ Maltodextrin } & \multicolumn{2}{|c|}{ Post-maltodextrin } \\
\hline & Mean & SD & Mean & SD & Mean & SD & Mean & SD & Mean & SD & Mean & SD \\
\hline Eub I-II-III & $10 \cdot 84$ & 0.1356 & $10 \cdot 94$ & 0.1310 & $10 \cdot 83$ & 0.1768 & $10 \cdot 81$ & 0.1806 & $10 \cdot 93$ & 0.1574 & $10 \cdot 86$ & 0.1554 \\
\hline Вас303 & 9.696 & 0.2489 & 9.608 & $0 \cdot 2817$ & $9 \cdot 534$ & 0.2274 & 9.609 & 0.2027 & 9.856† & 0.3680 & $9.539 \|$ & 0.1864 \\
\hline Ecyl387 & $9 \cdot 132$ & 0.2386 & $9 \cdot 132$ & 0.2386 & $9 \cdot 182$ & 0.2284 & $9 \cdot 155$ & 0.2426 & $9 \cdot 250$ & 0.2740 & $9 \cdot 210$ & 0.2584 \\
\hline Erec482 & $9 \cdot 749$ & $1 \cdot 643$ & $9 \cdot 812$ & 1.649 & $9 \cdot 857$ & $1 \cdot 651$ & $10 \cdot 06$ & 0.2217 & $10 \cdot 12$ & 0.2670 & $9 \cdot 813$ & $1 \cdot 648$ \\
\hline Bif164 & $9 \cdot 231$ & 0.3441 & $9 \cdot 681^{*}$ & $0 \cdot 2191$ & $9 \cdot 354 \dagger$ & 0.2823 & $9 \cdot 276$ & 0.3206 & 9.241† & 0.2799 & $9 \cdot 323$ & 0.2175 \\
\hline Ato291 & $9 \cdot 225$ & 0.4536 & $9 \cdot 677^{\star}$ & 0.3246 & 9.413 & 0.5510 & 9.547 & 0.4569 & $9.419 \dagger$ & 0.2705 & $9 \cdot 727$ & 0.2275 \\
\hline Clit135 & $7 \cdot 714$ & 0.2786 & $7 \cdot 767$ & 0.3538 & $7 \cdot 866$ & 0.3307 & $7 \cdot 861$ & 0.3894 & $7 \cdot 779$ & 0.3336 & $7 \cdot 588$ & 0.3583 \\
\hline Lab158 & 8.536 & 0.2044 & $8 \cdot 919^{*}$ & 0.2301 & $8 \cdot 373$ & 0.2160 & $8 \cdot 570$ & 0.2877 & $8 \cdot 149+\S$ & 0.3234 & 8.233 & 0.2747 \\
\hline EC1531 & $7 \cdot 188$ & 0.3784 & $7 \cdot 204$ & 0.4624 & $7 \cdot 183$ & 0.5049 & $7 \cdot 193$ & 0.4155 & $7 \cdot 142$ & 0.5030 & $7 \cdot 236$ & 0.5377 \\
\hline Prop853 & $9 \cdot 363$ & 0.3213 & $9 \cdot 455$ & 0.2216 & $9 \cdot 294$ & 0.2885 & $9 \cdot 302$ & 0.2728 & $9 \cdot 417$ & 0.2489 & $9 \cdot 225$ & 0.3079 \\
\hline Chis150 & $7 \cdot 727$ & 0.2669 & $7 \cdot 739$ & 0.4365 & $7 \cdot 830$ & 0.3587 & $7 \cdot 442$ & 0.3689 & $7 \cdot 755$ & 0.2988 & $7 \cdot 962$ & 0.3117 \\
\hline Rbro730-Rfla729 & $9 \cdot 894$ & 0.2174 & $9 \cdot 803$ & 0.3043 & $9 \cdot 684$ & 0.3496 & $9 \cdot 747$ & 0.3119 & $9 \cdot 672$ & 0.3304 & $9 \cdot 644$ & 0.2315 \\
\hline Ehal1469 & $8 \cdot 859$ & 0.2889 & $8 \cdot 840$ & 0.2664 & $8 \cdot 807$ & 0.3305 & $8 \cdot 842$ & 0.3012 & $8 \cdot 851$ & 0.3075 & $8 \cdot 846$ & 0.2815 \\
\hline Rrec584 & 9.583 & 0.2470 & $9 \cdot 612$ & 0.2702 & 9.575 & 0.2749 & 9.566 & 0.3059 & 9.549 & 0.3070 & $9 \cdot 552$ & 0.1890 \\
\hline
\end{tabular}

$\mathrm{VLCl}$, very-long-chain inulin.

* Mean value was significantly different from that for pre-VLCI $(P<0.05$; Tukey's post test).

† Mean value was significantly different from that for $\operatorname{VLCl}(P<0.05$; Tukey's post test).

$\ddagger$ Mean value was significantly different from that for post-VLCI $(P<0.05$; Tukey's post test).

$\S$ Mean value was significantly different from that for pre-maltodextrin $(P<0.05$; Tukey's post test)

\| Mean value was significantly different from that for maltodextrin $(P<0.05$; Tukey's post test). 
Table 3. SCFA concentrations measured by HPLC present in faecal samples collected from thirty-one volunteers over the course of the trial

(Mean values and standard deviations)

\begin{tabular}{|c|c|c|c|c|c|c|c|c|}
\hline \multirow[b]{2}{*}{ SCFA (mM) } & \multicolumn{2}{|c|}{ Pre-VLCI } & \multicolumn{2}{|c|}{$\mathrm{VLCl}$} & \multicolumn{2}{|c|}{ Pre-maltodextrin } & \multicolumn{2}{|c|}{ Maltodextrin } \\
\hline & Mean & SD & Mean & SD & Mean & SD & Mean & SD \\
\hline Acetic acid & 29.08 & $16 \cdot 45$ & $29 \cdot 68$ & $16 \cdot 71$ & $28 \cdot 57$ & $14 \cdot 73$ & $35 \cdot 4$ & $23 \cdot 04$ \\
\hline Propionic acid & 8.518 & 6.239 & $10 \cdot 19$ & 6.505 & $9 \cdot 252$ & $6 \cdot 88$ & $11 \cdot 21$ & $5 \cdot 711$ \\
\hline Butyric acid & $5 \cdot 299$ & $6 \cdot 061$ & 7.779 & $7 \cdot 825$ & 7.442 & $5 \cdot 651$ & $10 \cdot 95$ & 14.04 \\
\hline
\end{tabular}

$\mathrm{VLCl}$, very-long-chain inulin.

and butyric acids were observed over the course of the trial, neither between pre-inulin and inulin and maltodextrin and pre-maltodextrin nor when inulin or maltodextrin were compared.

\section{Analysis of bowel habit and gastrointestinal symptoms}

Table 4 summarises data on bowel habit and gastrointestinal symptoms, as recorded by the volunteers during intake of VLCI or maltodextrin. Stool frequency did not differ during inulin ingestion compared with placebo. Stool consistency, qualitatively graded by volunteers as hard, formed, or soft, varied greatly between individuals. No diarrhoea was reported by any subjects, while there was a significant increase in bloating upon ingestion of VLCI $(P<0 \cdot 05)$. However, on average, even the increased bloating was still rated as mild. There were no significant differences between treatments with regard to flatulence and abdominal pain. None of the gastrointestinal symptoms was severe enough for volunteers to discontinue the study.

\section{Gas production kinetics}

Fig. 3 shows the cumulative gas production at $3 \mathrm{~h}$ intervals for a $27 \mathrm{~h}$ fermentation period, in five randomly selected volunteers participating in the feeding study upon completion of treatments with VLCI and maltodextrin. In general, VLCI showed higher gas volumes than maltodextrin from $5 \mathrm{~h}$ onwards. There was a significant increase in the rate of gas production pattern during the first $5 \mathrm{~h}$ of in vitro fermentation, in particular with faecal samples after the intake of VLCI compared with the maltodextrin (Fig. 3).

Both treatment groups appeared to generate gas at $3 \mathrm{~h}$ after inoculation of faecal slurry and up to $27 \mathrm{~h}$ (Fig. 3).
The cumulative gas production after maltodextrin treatment was significantly lower up to $27 \mathrm{~h}$ fermentation as compared with VLCI. Apart from volunteer 4, samples of the other volunteers generated similar levels of cumulative gas production during the $24 \mathrm{~h}$ fermentation period. Volunteer 4 had markedly higher rates of gas production compared with the other donors.

The gas production pattern over the $27 \mathrm{~h}$ of incubation and the results of the cumulative gas production are presented in Table 5. Samples after VLCI intervention generated higher gas volume production (A) than after maltodextrin intervention with lower lag time and fractional degradation rate at 12 and $24 \mathrm{~h}$. These data are in accordance with bloating ratings recorded in the volunteers' diaries during the course of the trial.

\section{Discussion}

The bifidogenic nature of chicory inulin is very well established $^{(3,18,37-44)}$. Positive shifts in the composition of microflora have been shown in vivo in human studies at doses ranging from 4 to $40 \mathrm{~g} / \mathrm{d}^{(15-21)}$. While the majority of studies to date have investigated the effect of chicory inulin on the human gut microbiota using culture-based methodologies ${ }^{(3,18,19,45,46)}$, more recent studies have applied molecular methods such as FISH and real-time PCR for the bacterial analyses ${ }^{(14,47-55)}$.

However, the in vivo effect of globe artichoke-derived inulin in human subjects has not been studied to date. It is clear that globe artichoke inulin differs in DP distribution as well as in average $\mathrm{DP}^{(8)}$. Recent in vitro studies reported that DP may be a factor affecting not only the prebiotic efficacy of a substrate, but also its persistence in the colon and the manifestation of undesirable gastrointestinal side effects ${ }^{(56,57)}$. The inulin with the highest average DP to

Table 4. Summary of bowel habit and gastrointestinal symptom data for thirty volunteers over the course of the trialt (Mean values and standard deviations)

\begin{tabular}{|c|c|c|c|c|c|c|c|c|c|c|}
\hline & \multicolumn{10}{|c|}{ Bowel habit and gastrointestinal symptoms } \\
\hline & \multicolumn{2}{|c|}{$\begin{array}{l}\text { Stool number } \\
\text { (per d) }\end{array}$} & \multicolumn{2}{|c|}{$\begin{array}{c}\text { Stool } \\
\text { consistency }\end{array}$} & \multicolumn{2}{|c|}{$\begin{array}{l}\text { Abdominal } \\
\text { pain }\end{array}$} & \multicolumn{2}{|c|}{$\begin{array}{l}\text { Intestinal } \\
\text { bloating }\end{array}$} & \multicolumn{2}{|c|}{ Flatulence } \\
\hline & Mean & SD & Mean & SD & Mean & SD & Mean & SD & Mean & SD \\
\hline VLCI & $1 \cdot 34$ & 0.64 & $1 \cdot 30$ & 0.47 & $1 \cdot 13$ & 0.86 & $1 \cdot 33^{*}$ & 0.76 & $1 \cdot 24$ & 0.63 \\
\hline Maltodextrin & 1.45 & 0.57 & $1 \cdot 27$ & 0.45 & 0.83 & 0.59 & 0.87 & 0.57 & $1 \cdot 20$ & 0.55 \\
\hline
\end{tabular}

VLCl, very-long-chain inulin.

${ }^{*}$ Mean value was significantly different from that for maltodextrin $(P<0.05$; paired $t$ test, two-tailed).

$\dagger$ Analysis was performed by allocating numbers to defined conditions. Stool consistency: hard $=0$; formed $=1$; soft $=2$. Abdominal pain, bloating and flatulence: none $=0 ;$ mild $=1$; moderate $=2$; severe $=3$. 


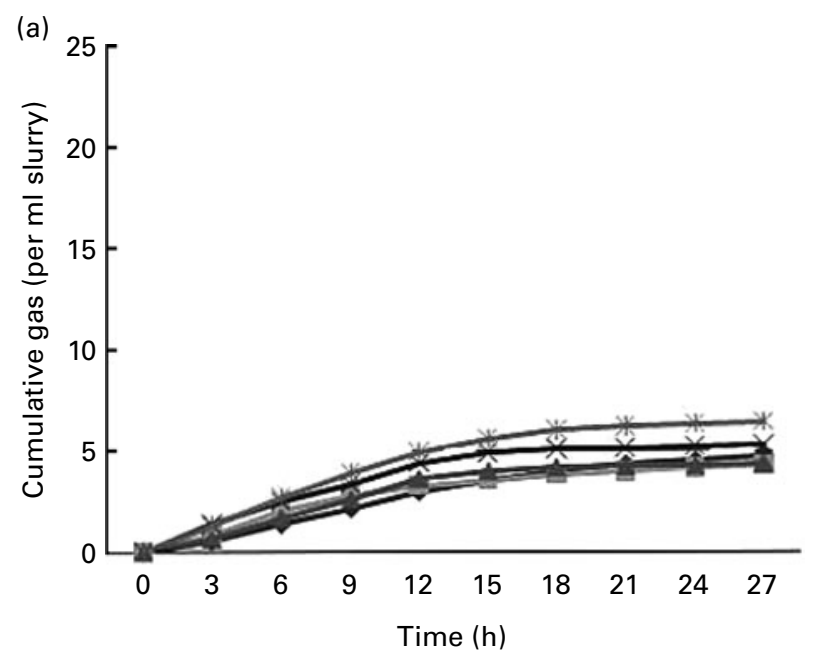

(b)

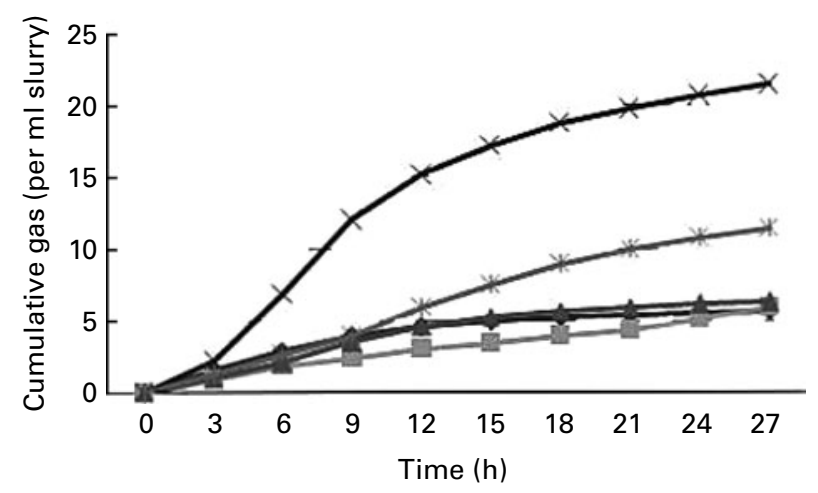

Fig. 3. Cumulative gas production over $27 \mathrm{~h}$ with maltodextrin (a) and verylong-chain inulin (b). Values are means of five volunteers (seven replicates for each volunteer on each respective treatment). $(\bullet-)$, Volunteer $1 ;(--)$, volunteer 2; $(\leftarrow)$, volunteer $3 ;(\rightarrow)$, volunteer 4 ; $(*)$, volunteer 5 .

be studied in vivo in human subjects so far has been Beneo ${ }^{\circledR} \mathrm{HP}^{(18,54)}$.

Using direct molecular-based enumeration of faecal bacteria, we have shown that VLCI derived from globe artichoke selectively stimulates the levels of faecal bifidobacteria. This is concordant with other in vivo intervention studies with fructans which often reported increases between $0 \cdot 5-1 \cdot 0 \log _{10}$ bifidobacteria counts ${ }^{(58)}$. However, the magnitude of increase seems to depend on the baseline values, and higher increases are often observed in volunteers with low initial bifidobacteria numbers ${ }^{(55)}$. While the bifidogenic potential is well proven, the effect of consumption of inulin on other bacterial groups is less well established. A decrease in Clostridia was mainly reported by culture-based bacteria analysis ${ }^{(3,47)}$; however, a recent study which used FISH also found decreased bacteria numbers for the $C$. histolyticum group and $C$. lituseburense group after inulin ingestion ${ }^{(14)}$. In the same study ${ }^{(14)}$ there was also a decrease in Bacteroides numbers after inulin consumption. We also found that Bacteroides numbers were significantly lower after VLCI than after maltodextrin intervention. Additionally, we observed a significant increase in lactobacilli-enterococci after VLCI treatment. While there was a small increase after inulin consumption in one human intervention trial ${ }^{(59)}$ and some indication from in vitro fermentation studies with inulins and fructo-oligosaccharides ${ }^{(60,61)}$ that the lactobacilli-enterococci group could be influenced by inulin, this is the first time that such a high increase in this bacterial group has been reported for inulin in a human intervention study. The only other bacterial group in the present study being stimulated after VLCI ingestion was Atopobium. The role of Atopobium in the human colon is not clear. However, they are commonly isolated from healthy human faeces and are present at $1.5-3 \%$ of the total faecal populations ${ }^{(62)}$. It is not clear from the results of the present study whether Atopobium can ferment VLCI or if the increase is due to cross-feeding between different bacterial groups. It is noteworthy that the increase in bifidobacteria and lactobacillienterococci in the present study were paralleled by a decrease in the levels of potentially harmful bacteria such as Bacteroides-Prevotella. As total bacterial levels remained unchanged throughout the study, changes upon VLCI ingestion appear to be inter-population only.

No differences were observed in faecal SCFA throughout the study. This is not surprising, as over $95 \%$ of SCFA produced in the human large intestine are thought to be rapidly absorbed within the colon, and only a small proportion of all SCFA produced in the large bowel is excreted in the faeces $^{(63,64)}$.

Several studies have shown that fermentation of inulin-type fructans may stimulate bowel movements and may normalise stool frequency ${ }^{(18-19,21)}$. Increased bloating and mild flatulence upon inulin-type fructan ingestion is a well-known and accepted side effect ${ }^{19,20,64-67)}$.

Analysis of the gastrointestinal symptom volunteer diaries indicates a significant increase in intestinal bloating during VLCI intake in healthy volunteers. The formation of $\mathrm{H}_{2}$,

Table 5. Gas production kinetics obtained by the in vitro fermentation of very-long-chain inulin (VLCl) and maltodextrin*

\begin{tabular}{|c|c|c|c|c|c|c|c|c|}
\hline \multirow{2}{*}{$\begin{array}{l}\text { Parameters... } \\
\text { Volunteer }\end{array}$} & \multicolumn{2}{|c|}{$A$} & \multicolumn{2}{|r|}{$\mathrm{T}$} & \multicolumn{2}{|c|}{$\mu 12$} & \multicolumn{2}{|c|}{$\mu 24$} \\
\hline & VLCl & Maltodextrin & VLCl & Maltodextrin & VLCI & Maltodextrin & VLCl & Maltodextrin \\
\hline 1 & $6 \cdot 06^{c}$ & $4.62^{c}$ & $1 \cdot 28^{d}$ & $1 \cdot 22^{b}$ & $0.046^{a}$ & $-0.002^{d}$ & $0.032^{a}$ & $-0.001^{b}$ \\
\hline 2 & $6.53^{\mathrm{c}}$ & $5 \cdot 40^{\mathrm{b}}$ & 0.03 & $1.75^{a}$ & $0.008^{b}$ & $0.065^{a}$ & $0.005^{b}$ & $0.046^{a}$ \\
\hline 3 & $6 \cdot 51^{\mathrm{c}}$ & $4.76^{\mathrm{C}}$ & $1.61^{\mathrm{C}}$ & $1.84^{a}$ & $-0.006^{c}$ & $-0.010^{c}$ & $-0.005^{c}$ & $-0.007^{d}$ \\
\hline 4 & $23.09^{a}$ & $5 \cdot 61^{\mathrm{b}}$ & $1.88^{\mathrm{b}}$ & $0.58^{c}$ & $-0.008^{c}$ & $0.005^{b}$ & -0.005 & $0.003^{c}$ \\
\hline 5 & $14 \cdot 08^{b}$ & $6 \cdot 65^{a}$ & $2 \cdot 33^{a}$ & $1 \cdot 12^{b}$ & $-0.006^{c}$ & $-0.002^{\mathrm{d}}$ & $-0.004^{c}$ & $-0.00^{\mathrm{b}}$ \\
\hline
\end{tabular}

a,b,c,d Values within a column with unlike superscript letters were significantly different $(P<0.05)$.

*Parameters obtained from the adjustment of gas production by France et al. ${ }^{(36)}$. Potential gas production $(\mathrm{A} ; \mathrm{ml})$; lag time (T; h), time to half-asymptote $(\mathrm{T} / 2 ; \mathrm{h})$ and fractional rate of gas production at $\mathrm{T} / 2(\mu ;$ per $\mathrm{h})$. 
which is a metabolic endproduct of bacterial fermentation in the colon, is probably the major cause of this symptom ${ }^{(14)}$.

However, it has to be emphasised that bifidobacteria, the numbers of which increased significantly with inulin, are not gas producers. Several studies have reported increased gas production upon the ingestion of inulin, which is not accompanied by a concomitant increase in gas-producing bacterial groups and the authors have commonly attributed this effect to consumer perception ${ }^{(54,55)}$. Therefore the gas-generating potential of samples obtained from a group of randomly selected volunteers was also followed in vitro, at baseline and at the end of each treatment.

The in vitro observations confirmed the in vivo reports, as after ingestion of VLCI the rate of gas production in faeces increased and led to higher cumulative gas levels compared with the maltodextrin faeces. VLCI selectively increased the faecal levels of bifidobacteria and lactobacilli-enterococci in vivo, whilst Clostridia, which are prolific gas producers in faeces, remained stable. However, increased gas production may be due to increased or altered metabolic activity of these bacteria facilitated probably by a higher availability of potential substrates such as acetate. Bacterial enumeration cannot account for possible increases in metabolic activity. Furthermore, there may be shifts at species levels promoting the growth of strains that possess higher gas-producing capacities. Further clarification of the relationship between specific intestinal bacteria and gas production as a result of colonic fermentation is required. In general, both maltodextrin and VLCI treatments were well accepted by the human volunteers and all subjects completed the study without severe side effects being noted.

The prebiotic ability of a VLCI may have further implications in vivo. While short-chain fructans are more rapidly fermented ${ }^{(61)}$, higher molecular weight and low solubility may improve persistence in the gut ${ }^{(56,68)}$. Thus, due to its physico-chemical characteristics - high molecular weight and low solubility - VLCI is expected to prolong saccharolytic fermentation into distal colonic areas and in vivo animal studies are under way to investigate the effect of VLCI on the site of fermentation and the selectivity compared with Beneo ${ }^{\circledR} \mathrm{HP}$.

In conclusion, the present study has demonstrated the prebiotic efficacy of VLCI from globe artichoke, which combined significant increases in the levels of both bifidobacteria and lactobacilli in a selective manner with little adverse gastrointestinal effects at $10 \mathrm{~g} / \mathrm{d}$.

\section{Acknowledgements}

We would like to extend our gratitude to the volunteers who participated in the present study. The study was financially supported by Bayer Group.

A. C. was the principal investigator for conducting the experiment and writing the manuscript. A. K. contributed to data interpretation, manuscript preparation and the literature search. S. K. contributed to the analysis of in vitro rate of gas production. G. R. G. supervised the study design along with drafting the manuscript. E. G. contributed to the analysis of VLCI by the GPC-RI MALLS and HPAEC-PAD methods. V. L. was the overall coordinator of the VLCI project. M. B. was responsible for the preparation of the VLCI material (harvest, isolation, purification, quality check). C. F. was involved in the functionality testings of VLCI. All other authors provided suggestions, alterations to the manuscript and comments for the analyses.

E. G., C. F., M. B. and V. L. were Bayer Group (Bayer BioScience $\mathrm{GmbH}$ and Bayer Cropscience AG) employees at the time of the study who functioned as coordinators of this sponsored project. There were no conflicts of interest that affected the design, the execution of the study protocol, analyses or interpretation of the data. None of the other authors has any conflicts of interest to declare.

\section{References}

1. Kolida S, Saulnier DMA \& Gibson GR (2006) Gastrointestinal microflora: probiotics. Adv Appl Microbiol 59, 187-219.

2. Hamilton-Miller JMT (2001) A review of clinical trials of probiotics in the management of inflammatory bowel disease. Infect Dis Rev 3, 83-87.

3. Gibson GR \& Roberfroid MB (1995) Dietary modulation of the human colonic microbiota introducing the concept of prebiotics. J Nutr 125, 1401-1412.

4. Gibson GR, Probert HM, Van Loo JAE, et al. (2004) Dietary modulation of the human colonic microbiota: updating the concept of prebiotics. Nutr Res Rev 17, 257-259.

5. Roberfroid R (2007) Prebiotics: the concept revisited. J Nutr 137, 830S-837S.

6. Rastall RA \& Maitin V (2002) Prebiotics and synbiotics: towards the next generation. Curr Opin Biotechnol 13, 490-498.

7. Gibson GR, Berry Ottaway P \& Rastall RA (2000) Prebiotics: New Developments in Functional Foods. Oxford: Chandos Publishing Ltd.

8. Van Loo J, Coussement L, de Leenheer H, et al. (1995) On the presence of inulin and oligofructose as natural ingredients in the Western diet. Crit Rev Food Sci Nutr 35, 525-552.

9. Praznik W, Beck H \& Eigner W (1987) New high-performance gel permeation chromatographic system for the determination of low-molecular weight amyloses. J Chromatogr 387, 467-472.

10. Praznik W, Beck RHF \& Nitsch E (1984) Determination of fructan oligomers of degree of polymerization $2-30$ by HPLC. J Chromatogr 303, 417.

11. Raccuia SA \& Melilli MG (2004) Cynara radunculus L., a potential source of inulin in the Mediterranean environment: screening of genetic variability. Aus J Agric Res 55, 693-698.

12. Hellwege EM, Czapla S, Jahnke A, et al. (2000) Transgenic potato (Solanum tuberosum) tubers synthesize the full spectrum of inulin molecules naturally occurring in globe artichoke (Cynara scolymus) roots. PNAS 97, 8699-8704.

13. Frese L (1993) Production and utilization of inulin part I. Cultivation and breeding of fructan-producing crops. In Science and Technology of Fructans, pp. 303-318 [M Suzuki and NJ Chatterton, editors]. Boca Raton, FL: CRC.

14. Kleessen B, Schwarz S, Boehm A, et al. (2007) Jerusalem artichoke and chicory inulin in bakery products affect faecal microbiota of healthy volunteers. Br J Nutr 98, 540-549.

15. Williams CH, Witherly SA \& Buddington RK (1994) Influence of dietary neosugar on selected bacteria groups of the human fecal microbiota. Microb Ecol Health Dis 7, 91-97.

16. Gibson GR, Beatty ER, Wang X, et al. (1995) Selective stimulation of bifidobacteria in the human colon by oligofructose and inulin. Gastroenterology 108, 975-982.

17. Buddington RK, Williams CH, Chen SC, et al. (1996) Dietary supplement of neosugar alters the fecal flora and decreases the activities of some reductive enzymes in human subjects. Am J Clin Nutr 163, 709-716. 
18. Kleessen B, Sykura B, Zunft HJ, et al. (1997) Effects of inulin and lactose on fecal microflora, microbial activity and bowel habit in elderly constipated persons. Am J Clin Nutr 65, 1397-1402.

19. Bouhnik Y, Vahedi K, Achour L, et al. (1999) Short-chain fructooligosaccharide administration dose dependently increases fecal bifidobacteria in healthy humans. J Nutr 129, 113-116.

20. Kruse HP, Kleessen B \& Blaut M (1999) Effects of inulin on faecal bifidobacteria in human subjects. Br J Nutr 82, 375-382.

21. Den Hond E, Geypers B \& Ghoos Y (2000) Effect of high performance inulin on constipation. Nutr Res 20, 731-736.

22. Cummings JH, Macfarlane GT \& Englyst HN (2001) Prebiotic digestion and fermentation. Am J Clin Nutr 73, 415S-420S.

23. Brandt LA (2001) Prebiotics enhance gut health. Prepared Foods 170, NS7-NS10.

24. Blaut M (2002) Relationship of prebiotics and food to intestinal microflora. Eur J Nutr 41, Suppl. 1, I11-I16.

25. Martín-Peláez S, Gibson GR, Martín-Orúe SM, et al. (2008) In vitro fermentation of carbohydrates by porcine faecal inocula and their influence on Salmonella typhimurium growth in batch culture systems. FEMS Microbiol Ecol 66, 608-619.

26. Langendijk PS, Schut F, Jansen GJ, et al. (1995) Quantitative fluorescence in situ hybridization of Bifidobacterium spp. with genus-specific 16S rRNA-targeted probes and its application in fecal samples. Appl Environ Microbiol 61, 3069-3075.

27. Harmsen HJM, Elfferich P, Schut F, et al. (1999) A 16S rRNAtargeted probe for detection of lactobacilli and enterococci in fecal samples by fluorescent in situ hybridization. Microbiol Ecol Health Dis 11, 3-12.

28. Manz W, Amann R, Ludwig W, et al. (1996) Application of a suite of $16 \mathrm{~S}$ rRNA-specific oligonucleotide probes designed to investigate bacteria of the phylum Cytophaga-FlavobacterBacteroides in the natural environment. Microbiology 142, 1097-1106.

29. Franks AH, Harmsen HJ, Raangs GC, et al. (1998) Variations of bacterial populations in human feces measured by fluorescent in situ hybridization with group-specific 16S rRNA-targeted oligonucleotide probes. Appl Environ Microbiol 64, 3336-3345.

30. Harmsen HJ, Raangs GC, He T, et al. (2002) Extensive set of 16S rRNA-based probes for detection of bacteria in human feces. Appl Environ Microbiol 68, 2982-2990.

31. Harmsen HJM, Wildeboer-Veloo ACM, Grijpstra J, et al. (2000) Development of 16S rRNA based probes for the Coriobacterium group and the Atopobium cluster and their application for enumeration of Coriobacteriaceae in human feces from volunteers of different age groups. Appl Environ Microbiol 66, 4523-4527.

32. Amann RI, Binder BJ, Olson RJ, et al. (1990) Combination of 16S rRNA-targeted oligonucleotide probes with flow cytometry for analyzing mixed microbial populations. Appl Environ Microbiol 56, 1919-1925.

33. Walker AW, Duncan SH, Leitch ECM, et al. (2005) $\mathrm{pH}$ and peptide supply can radically alter bacterial populations and short-chain fatty acid ratios within microbial communities from the human colon. Appl Environ Microbiol 71, 3692-3700.

34. Mauricio RM, Mould FL, Dhanoa MS, et al. (1999) Semiautomated in vitro gas production technique for ruminant feedstuff evaluation. Anim Feed Sci 89, 33-48.

35. Macfarlane T, Macfarlane S \& Gibson GR (1998) Validation of a three-stage compound continuous culture system for investigating the effect of retention time on the ecology and metabolism of bacteria in the human colon. Microb Ecol 35, 180-187.

36. France J, Dijkstra J, Dhanoa MS, et al. (2000) Estimating the extent of degradation of ruminant feeds from a description of their gas production profiles observed in vitro: derivation of models and other mathematical considerations. Br J Nutr 83, $143-150$
37. Bouhnik Y, Flourié B, Ouarne F, et al. (1994) Effects of prolonged ingestion of fructo-oligosaccharides on colonic bifidobacteria, fecal enzymes and bile acids in humans. Gastroenterology 106, A598-A604.

38. Hidaka H, Eida T, Takizawa T, et al. (1986) Effects of fructooligosaccharides on intestinal flora and human health. Bifid Microflora 5, 37-50.

39. Mitsuoka T, Hata Y \& Takahashi Y (1986) Effects of long-term intake of neosugar on intestinal flora and serum lipids. In Proceedings of the 3rd Neosugar Research Conference, Tokyo, Japan, topic 1-4, pp. 1-8. Tokyo: Meiji-Seika Publications.

40. Mitsuoka T, Hidaka H \& Eida T (1987) Effect of fructooligosaccharides on intestinal microflora. Nahrung 31, 426-436.

41. Sanno T (1986) Effects of neosugar on constipation, intestinal microflora and gallbadder contraction in diabetics. In Proceedings of the 3rd Neosugar Research Conference, Tokyo, Japan, pp. 109-117. Tokyo: Meiji-Seika Publications.

42. Roberfroid MB, Van Loo J \& Gibson GR (1998) The bifidogenic nature of chicory inulin and its hydrolysis products. J Nutr 128, 11-19.

43. Shimoyama T, Hori N, Kawaura A, et al. (1984) Relationship between neosugar $\mathrm{P}$ and chronic constipation. In Proceedings of the 2nd Neosugar Research Conference, Toyko, Japan, topic 3-2. Tokyo: Meiji-Seika Publications.

44. Takahashi Y (1986) Effects of neosugar in the chronic renal failure patient. In Proceedings of the 3rd Neosugar Research Conference, Tokyo, Japan, topic 1-3. Tokyo: Meiji-Seika Publications.

45. Ramirez-Farias C, Slezak K, Fuller Z, et al. (2009) Effect of inulin on the human gut microbiota: stimulation of Bifidobacterium adolescentis and Faecalibacterium prausnitzii. Br J Nutr 101, 541-550.

46. Brighenti F, Casiraghi MC, Canzi E, et al. (1999) Effect of consumption of a ready-to-eat breakfast cereal containing inulin on the intestinal milieu and blood lipids in healthy male volunteers. Eur J Clin Nutr 53, 726-733.

47. Yap WKW, Mohamed S, Husni JM, et al. (2008) Changes in infants faecal characteristics and microbiota by inulin supplementation. J Clin Biochem Nutr 43, 159-166.

48. Bouhnik Y, Raskine L, Simoneau G, et al. (2006) The capacity of short-chain fructo-oligosaccharides to stimulate faecal bifidobacteria: a dose-response relationship study in healthy humans. Nutr $J \mathbf{5}, 8$.

49. Moro G, Minoli I, Mosca M, et al. (2002) Dosage-related bifidogenic effects of galacto- and fructooligosaccharides in formula-fed term infants. J Pediatr Gastroenterol Nutr 34, 291-295.

50. Boehm G, Lidestri M, Casetta P, et al. (2002) Supplementation of a bovine milk formula with an oligosaccharide mixture increases counts of faecal bifidobacteria in preterm infants. Arch Dis Child Fetal Neonatal Ed 86, F178-F181.

51. Knol J, Scholtens P, Kafka C, et al. (2005) Colon microflora in infants fed formula with galacto- and fructo-oligosaccharides: more like breast-fed infants. J Pediatr Gastroenterol Nutr 40, 36-42.

52. Alles MS, Hartemink R, Meyboom S, et al. (1999) Effects of transgalactooligosaccharides on the composition of the human intestinal microflora and on putative risk markers for colon cancer. Am J Clin Nutr 69, 980-991.

53. Ito M, Deguchi Y, Miyamori A, et al. (1990) Effects of administration of galactooligosaccharides on the human faecal microflora, stool weight and abdominal sensation. Microb Ecol Health Dis 3, 285-292.

54. Tuohy KM, Kolida S, Lustenberger A, et al. (2001) The prebiotic effects of biscuits containing partially hydrolyzed guar gum and fructooligosaccharides - a human volunteer study. Br J Nutr 86, 341-348. 
55. Kolida S, Meyer D \& Gibson GR (2007) A double-blind placebo-controlled study to establish the bifidogenic dose of inulin in healthy humans. Eur J Clin Nutr 61, 1189-1195.

56. Van De Wiele T, Boon N, Possemiers S, et al. (2007) Inulin-type fructans of longer degree of polymerization exert more pronounced in vitro prebiotic effects. J Appl Bacteriol 102, 452-460.

57. Hughes SA, Shewry PR, Li L, et al. (2007) In vitro fermentation by human faecal microflora of wheat arabinoxylans. J Agric Food Chem 55, 4589-4595.

58. Kolida S \& Gibson GR (2007) Prebiotic capacity of inulinfructans. J Nutr 137, 2503S-2506S.

59. Ramnani P, Gaudier E, Bingham M, et al. (2010) Prebiotic effect of fruit and vegetable shots containing Jerusalem artichoke inulin: a human intervention study. Br J Nutr 104, 233-240.

60. Probert HM, Apajalahti JHA, Rautonen N, et al. (2004) Polydextrose, lactitol, and fructo-oligosaccharide fermentation by colonic bacteria in a three-stage continuous culture system. Appl Environ Microbiol 70, 4505-4511.

61. Gomez E, Tuohy KM \& Gibson GR, et al. (2009) In vitro evaluation of the fermentation properties and potential prebiotic activity of Agave fructans. J Appl Microbiol (epublication ahead of print version 4 November 2009).
62. Leitch McWilliam EC, Walker AW, Duncan SH, et al. (2007) Selective colonization of insoluble substrates by human faecal bacteria. Environ Microbiol 9, 667-679.

63. Salminen S, Bouley C, Boutron-Ruault MC, et al. (1998) Functional food science and gastrointestinal physiology and function. Br J Nutr 80, S147-S171.

64. Coussement PAA (1999) Inulin and oligofructose: safe intakes and legal status. J Nutr 129, 1412S-1417S.

65. Bruhwyler J, Carrer F, Demanet E, et al. (2008) Digestive tolerance of inulin-type fructans: a double-blind, placebocontrolled, cross-over, dose-ranging, randomized study in healthy volunteers. Int J Food Sci Nutr 60, 165-175.

66. Ripoll C, Flourié B, Megnien S, et al. (2009) Gastrointestinal tolerance to an inulin-rich soluble roasted chicory extract after consumption in healthy subjects. Nutrition (epublication ahead of print version 20 November 2009).

67. Van den Heuvel EGHM, Schaafsma G, Muys T, et al. (1998) Non-digestible oligosaccharides do not interfere with calcium and nonheme-iron absorption in young, healthy men. Am J Clin Nutr 67, 445-451.

68. Roland N, Nugon-Baudon L, Andrieux C, et al. (1995) Comparative study of the fermentative characteristics of inulin and different types of fibre in rats inoculated with a human whole faecal flora. Br J Nutr 74, 239-249. 